\title{
Am I an Online Shopper After All? A Paradox on Definition of e-Commerce from the Consumers' Perspective
}

\author{
Chun-An Chen \\ Nan-Ya Institute of Technology \\ E-Mail: cachen@nanya.edu.tw \\ Jui-Chin Jiang \\ Chung-Yuan Christian University \\ E-Mail: jcjiang@cycu.edu.tw
}

\begin{abstract}
Retailing marketplace today is composed of traditional and electronic retailers. Facing to the evolutionary transformation arose from electronic commerce (EC), this article attempts to establish the elementary understanding on EC and modern consumers' behavior. The authors examine the gap between practitioners' and academics' perception about EC and get a clear look from consumers' perspective. Four behavioral patterns with different tendency to online activities are further identified. They are product-, price-, convenience-, and service-orientation. Additionally, an industrial demonstration of consumer electronics retailing is presented to show the gap and to exemplify an application of consumers' behavioral patterns proposed in this paper. For people involved in the marketing and EC fields, this article suggests that consumer behavior should be reexamined according to the specific product categories under appropriate EC definition.
\end{abstract}

Keywords: Electronic Commerce, Consumer Behavior, Online Retailing

\section{INTRODUCTION}

Consider the scenario that I interact with sellers intensively over the Internet in my purchase process and claim to my friends, with a little bit arrogance, that I am a modern online shopper. How surprised am I while being notified that my deal is not qualified to be formal electronic commerce (EC) just because I chose a physical shop to transact at last moment? 
Similar embarrassing situation happen to some of the retailers. Let us examine those conventional stores who successfully employ electronic marketing tools to enhance their sales but complete all their transactions with customers off-line. Their efforts therefore, by general perceptions, have no contribution to the expanding scale of EC.

After all, what's the problem within the paradox on definition of EC in common practice?

\section{AN ARGUMENT ON EXISTING EC DEFINITIONS}

A simple search conducted on Google.com by the query keyword: "definition AND electronic commerce" responded with 25,500,000 results from sources covering public, educational and commercial websites (March 2006). Unfortunately, Most of them indefinitely defined EC from the business perspective such as: "any transaction completed over a computer-mediated network that involves the transfer of ownership or rights to use goods or services" (census.gov, US Census Bureau), "any transactions conducted over the Internet or through the Internet access" (euro.ecom.cmu.edu, Institute for eCommerce, Carnegie Mellon University, Pittsburgh), and "Commerce that is transacted electronically, as over the Internet” (answers.com, an U.S. based online corporate).

Considering the need to statistically measure the scale of e-commerce across countries, Colecchia (1999) had proposed the OECD methodology to define EC. Definitions were classified in his working paper from the business or industry, public statistical offices, and policy makers' points of view. Unfortunately, key characteristics of consumers' online behavior were not captured in his work. Most recently, Turban et al. (2006) have defined EC also from the business perspective as: "the process of buying, selling, transferring, or exchanging products, services, and/or information via networks, including the Internet”. They also have stated the opinion that using the term "e-business" to refer to a broader definition of EC. According to McKay \& Marshall (2004), e-business is the use of the Internet and other information technologies to support commerce and improve business performance. This definition on EC is extended to cover the digitalization of business process but, however, it is still from the businesses' perspective rather than the consumers'.

Today, marketers still do not have a good grip of online consumer's real need, and consequently, their purchasing behavior. This is true even for those who have already been in the electronic market (Gupta et al., 2004; Lee, 2002). Therefore, it is clear that the understandings of Internet-assisted purchase activities performed by 
up-to-date consumers have become the emergent challenge for practitioners and academics (Constantinides, 2004). By reviewing these common EC definitions well accepted by practitioners and researchers, it is learned that a conceptual discrepancy existed in two different scopes of identification from the consumers' perspective. The strict one with narrow scope identifies all the transactions been confirmed or completed online as qualified EC events. Almost all the market statistics about online sales are results under this assumption. Another generalized definition widely applied by most of the scholars broadens the scope to accept all the people participate in the electronic interfaces as qualified online shoppers.

Confusion arises consequently from the different identifications. One of the common examples in practice is the subjective but misunderstood belief that attracting buyers' online interactions absolutely implies their online purchasing. However, marketing managers that adopt the strict definition may be challenged on their performances of EC just because some of their achievements from online marketing are closing account in physical channel and therefore be eliminated from the online sales. Besides, from the macro point of view, some underestimated statistics about EC market scale may probably be erroneously adopted by people and, as a result, lead to the consequence of depreciation on influences from EC.

In contrast to the practitioners, there are also some confusions happened to academics due to their broader sense of EC. Most of the previous researchers made inferences under the presupposition that buyers involved in any part of online interactions with sellers are the online shoppers, no matter how "traditional" they are. Based on this definition, electronic market's characteristics and online consumers' behavior are thought by a majority of researchers as entirely independent from traditions. This is likely to cause the misunderstanding about behavioral nature of consumers existed in the compound marketplace and consequently bringing blemished outcomes.

\section{RESEARCH MOTHOD}

In this study, the authors applied the focus group method to investigate consumers' perception about EC and their online behavioral patterns. The focus group is a research method generally utilized by researchers and practitioners to perform qualitative analysis or exploratory study in the fields of marketing, education, management, decision-making, and other social science issues. The results obtained from the focus group studies are particularly effective in supplying information about how people think, feel, or act regarding a specific topic (Freitas et al., 1998). The 
function of the group may be to suggest ideas, to clarify potential options, to react to ideas, to recommend a course of action, to make a decision, to plan, or to evaluate. (Krueger \& Casey, 2000)

Over 1,000 evening school university students were screened and twenty-four samples were selected. The selection criterions included the ability to utilize the Internet resources, purchasing power, communication skill, and availability. They all have stable income from their full-time or part-time jobs, and they can make purchase decision independently. All samples are arranged into three subgroups randomly. Each group consisted of eight participants. Three sessions of focus group interviews were conducted, each with one group.

The issues discussed in the interviews were organized in advance to prevent the logical mistakes on follow-up analysis. Discussions covered issues about the convenience to use the Internet resources, tendency to perform online information search and evaluation before purchase, experience of online shopping, intentions of on-line behavior and experienced benefits, and factors influencing the channel choices. As in most focus group studies, the participants offered additional viewpoints beyond above investigation scheme/scope during the open discussion. All of the contributions from interviews not only provided insights into the consumers' behavioral patterns before purchase, but also inspired the re-confirmation of EC definition from consumers' perspective.

For the exploratory nature of this study, focus groups are applied as the tools to explore the behavioral characteristics of modern consumers. While adopting the convenient sampling from university students, respondents undoubtedly have the tendency towards higher frequency of Internet usage and more involvement on purchase. However, these younger students are just enough to represent the modern consumers existed in the compound marketplace and to reveal the evolvement in consumer behavior.

\section{SKETCH OF THE COMPOUND MARKETPLACE}

According to the results of the focus group interviews, a clear message shows that consumer's behavior has evolutionary changed due to availability of the Internet. In spite of abundant publications and literatures focused on the issues relating to EC, most of the theoretical and practical opinions, however, were proposed from the businesses' perspective rather than the consumers'. Some of them lack of an elementary knowledge about the compound nature of marketplace today. On the other word, conventional brick-and-mortar shops and electronic grocery stores coexist and 
compete to each other in the modern compound market. For the purpose to describe clearly from the consumers' perspective, the evolutionary effect of EC on traditional marketplace is illustrated in Figure 1.

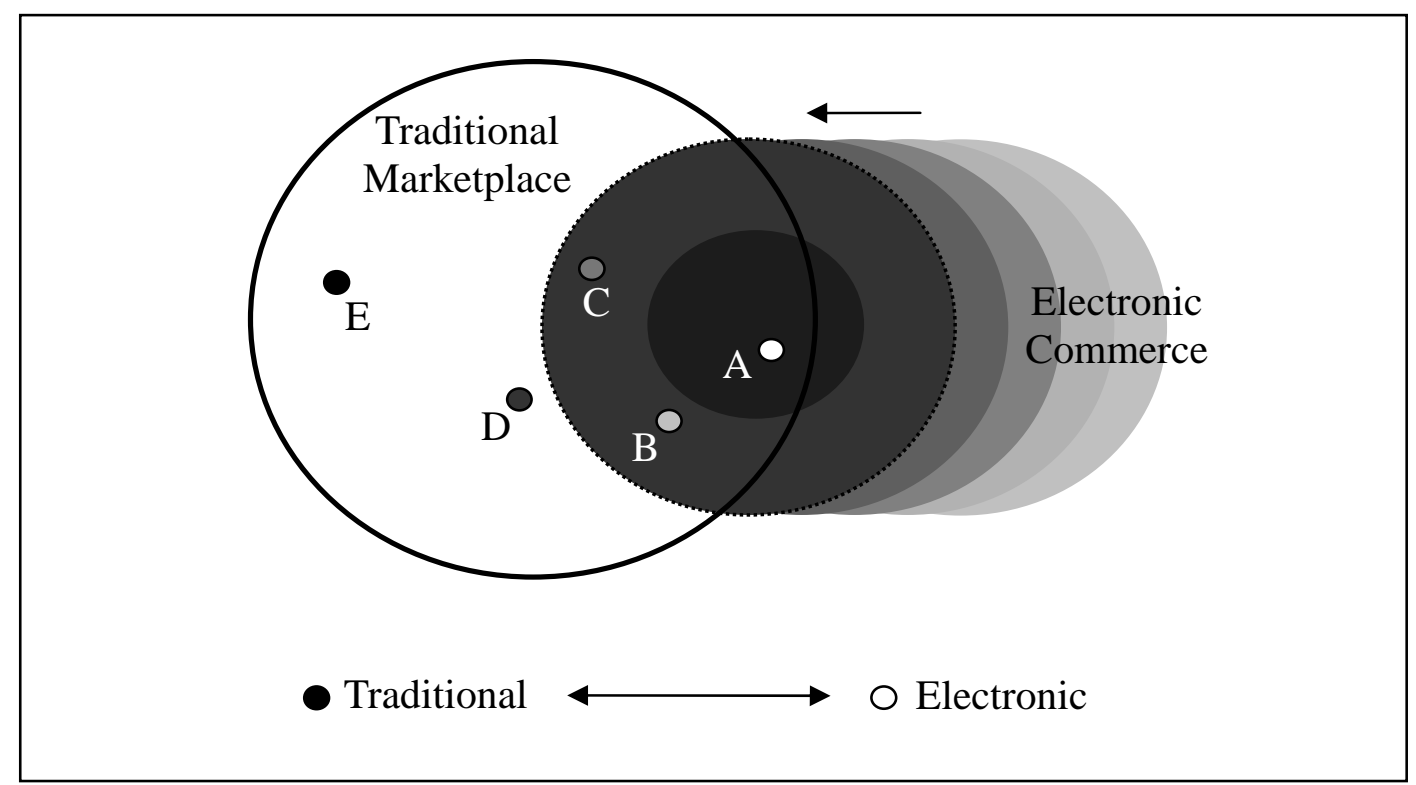

Figure 1 Compound marketplace with consumers today

Let us consider the consumers depicted in Figure 1. All buyers with marks from A to $\mathrm{D}$, in the illustration, are originally existed in traditional marketplace. This is the scenario of about ten years ago. While the tides of EC surged over the boundary and part of the people in front began to change their ways to purchase both conceptually and behaviorally. Buyers A with IT background is firstly overwhelmed by EC's availabilities and extensively transfer most of his/her purchase activities and deals into electronic channels. Suppose that buyer B and buyer C are the consumers drifted into the Internet wave but have no preference or familiarity on channel types. They both perform online interactions such as information search and evaluation before purchase and, perhaps, have different channel choices: buyer B chooses an online shop at last and buyer $\mathrm{C}$ deals with an off-line one. Anyway, there are still persons in modern marketplace like buyers D and $\mathrm{E}$ in the illustration not getting in touch with EC yet (the authors speculate that some of them are likely to be old folks or fogies). However, buyer $\mathrm{D}$ is on the verge of tide and very likely to be online before long but buyer $\mathrm{E}$, probably, will never get into.

By both definitions of EC mentioned above, buyer A is no doubt to be classified as a typical online shopper while buyers D and $\mathrm{E}$ are off-line. However, situations of buyer B and buyer C, the multi-channel shoppers (Schoenbachler \& Gordon, 2002), 
seem to be more complicated. From the narrow point of view, transaction performed by buyer B is accepted as EC for he/she chooses the online shop, no matter how less effort he/she made online. In contrast, buyer C's deal is unqualified to be an EC event just because one of the physical stores wins the final order, even though his/her decision heavily rely on support from the Internet. However, different result of identification will be generated when adopting broad definition. Both buyers B and C are accepted by most of the researchers as online shoppers participated in EC and are taken into the studies' considerations due to their online manners.

To date, more and more consumers behave like buyers $\mathrm{B}$ and $\mathrm{C}$ in the above illustration. They experience the convenience from the Internet and therefore interact online with sellers after recognizing their needs to purchase, but not necessarily select online channel at last moment. For the time being, not many people have preference or familiarity on electronic channel and therefore usually select online transactions, like the buyer A. The tendency toward EC will be conspicuous gradually. Plenty of consumers are likely to adopt it as buyer $\mathrm{D}$ eventually but there are still people never join, like buyer $\mathrm{E}$ in the illustration.

As a result of emerging importance of EC, many practitioners and academics put considerable efforts on studying behavior of online shoppers (as buyers A, B, and C) and further attempt to attract people standing by waves (as buyer D) to get into. Considerable quantity of literatures worked on the antecedents of online shopping Chang, et al. (2005) achieved a systematic work to summarize the previous researches and proposed reference models to describe online shoppers' behavior and its influencing factors. Unfortunately, most of them did not correctly recognize different natures of buyers discussed above and therefore make improper inference under the indefinite assumptions. For example, some of the influencing factors such as websites' information content and consumers' level of Internet usage will only promote buyers' online activities instead of online purchase, so that online sales will not increase accordingly. The other factors, such as buyers' trust to online retailers and security of transaction, are likely to have positive effects on consumers' final choice on online channel, and therefore contribute to the online sales.

Furthermore, difference about the research scope should be incorporated into consideration by researchers. For example, the efforts put on promoting consumer's overall trust on electronic environment benefit little to specific online retailer. In fact, enhancement of overall trust to EC should be the responsibility of government. What the individual retailer really concerns is consumers' concentrated trust and loyalty. Researchers have to clearly identify the scope and purpose of their research problems 
first, and then study the effect of factors on EC. From both practical and theoretical points of view, the conceptual clarification about consumers and marketplace presented in this article could contribute to avoid some of the logical contradictions hopefully.

\section{FOUR BEHAVIORAL PATTERNS OF CONSUMERS}

Based on discussion above, there obviously is a gap between practitioners' and academics' perception on EC. For the purpose to get a clear look on this situation, an elementary reexamination on behavior of modern consumers is achieved from the focus group interviews. According to the statements from respondents, four behavioral patterns are experimentally identified in this paper as follows.

1. Product-oriented: Consumers care about value delivered by seller from product-related attributes, including brand, specification, and function. They extensively search and obtain product knowledge over the Internet to support their evaluation and decision. Price sensitivity tends to be low in their product information search stage (but maybe not any more in later stages).

2. Price-oriented: Buyers search and evaluate price information from a large number of websites, with focus on their targeted products. Price sensitivity is significantly high due to their price comparison behavior. The result of buyers' economic concerns is fiery price competition in the retailing market.

3. Convenience-oriented: Consumers' focus is on the convenience, i.e., less time they need to spend in purchase and delivery. Price sensitivity is relatively low in this pattern. Some key points that consumers mostly concern are friendliness of sites' interfaces, efficiency of delivery and payment, and time to processing order.

4. Service-oriented: Buyers take services and securities provided by retailers as their priorities. Reputation of retailers (which can ensure the security of transaction) and level of service (covers whole transaction process) are two of the attributes they care about most. Price, relative to service, tends to be less sensitive for behavior of this pattern.

The result of behavioral classification above could be applied theoretically on many aspects of modern consumer issues. For example, the possibility of EC adoption by consumers, both from the process or result perspectives, is different with respect to different behavioral orientations. Product- and price-oriented consumers tend to perform online interactions with sellers for the purpose to obtain information about 
product and price. Because of the transparency nature of information over the Internet, these two types of consumers can easily achieve comparison and evaluation works. However, it is worthy to remind again that extensive online activities will not necessarily imply that their final choice is online channel (e.g. buyers B and C in illustration discussed earlier). In addition, convenience-oriented buyers also prefer online activities for the consideration of less time spent on purchase, and therefore likely to establish preference and familiarity on online retailers (e.g. buyer A). Finally, the possibility of EC adoption by service-oriented consumers is significantly low (e.g. buyers $\mathrm{D}$ and $\mathrm{E}$ ). This, somehow, can be referred to their trust on services provided by physical brick-an-mortar stores. The inference especially inspires all the marketers that service provided by online shops still needs improvement for the time beings. In most cases, lower service level is a result from less profitability of online retailers due to relatively higher price competition.

However, consumers' decision processes in real world are not as simple as mentioned above. Most of them incorporate multiple concerns in different stage during the transactions. Researchers and practitioners can flexibly apply these behavioral patterns to their interested investigations depending on product categories, demographic characteristics, and social/culture diversities. Four examples of binary applications based on above patterns are introduced:

1. Product-price: Consumers pay attention to evaluating products according to their needs first, and then proceed with price comparisons focused on the candidates. This is often seen in standardized product markets under multi-brand competition such as mobile phone, electronic devices, and computer peripherals.

2. Product-service: Products are first evaluated by consumers and service following. This is a common situation in markets of precious and durable goods such as insurances, electric appliances, and cars.

3. Product-convenience: Buyers tend to consider products attributes and expect a convenient transaction. Product categories such as PCs, consumer electronics, gifts, flowers, costume and accessories usually agree with this binary behavioral pattern.

4. Price-convenience: Price sensitivity is high and convenience is another requirement of these consumers. It mostly occurs in the market of homogeneous commodities at lower price such as household necessaries, books, and audio/video CDs. It is a special case that purchase of airlines tickets is also this type although its price is higher. 
Summarizing the discussions above, this article attempts to achieve a clarification on modern consumer behavior under the EC environment. While applying the result of consumer behavioral patterns, one thing need to be noticed is consumers' uncertainty with channel selection except those minorities with existed preference on traditional/electronic transactions. For confronting the fact that more and more consumers extensively search and evaluate online to support their purchase decision, all the marketers can only endeavor to participate the "online games", trying to reach their targeted customers by exposing themselves (at least providing enough information) electronically and actively. Until delivered value can fully satisfy targeted buyers' needs before, within, and after purchase, firms competing in modern compound marketplace will win the final successes.

\section{A DEMONSTRATION OF CONSUMER ELECTRONICS RETAILING}

All the public organizations, research institutes and independent researchers declared that the scale of EC would continue growing rapidly in the near future. According to U.S. Census Bureau News (Feb. 2006), U.S. EC sales for 2005 were estimated at $\$ 86.3$ billion, an increase of 24.6 percent from 2004. Besides, EC sales accounted for 2.3 percent of total U.S. retail sales in 2005 (about \$3,775 billion). The recognition of EC sales adopted by U.S. Census Bureau in their survey is a relatively narrow definition of EC from consumer perspective:

E-commerce sales are sales of goods and services where an order is placed by the buyer or price and terms of sale are negotiated over an Internet, extranet, Electronic Data Interchange (EDI) network, electronic mail, or other online system. Payment may or may not be made online.

This definition is narrow because only the transactions confirmed by buyer and seller under electronic base are qualified as EC events. However, it is not the narrowest one as those online deals with off-line payments are still accepted.

Furthermore, the proportion of EC on total retail sales is significantly affected by product categories. According to a recent study by the Consumer Electronics Association (CEA), while an average of 5 percent of all consumer electronics purchases are made online, certain product categories such as PCs, digital cameras and MP3 players sell more than 10 percent of product through online channels (TWICE, 2005a). Anyway, can these proportions represent the real impact of EC on retailing market and consumer behavior? 
Corresponding to the illustration discussed previously, the total retail sales covered all transactions undertaken by buyers from A to E. Furthermore, EC sales were calculated under the narrow definition of EC that covered all transactions completed from online channels (explained by buyers A and B). This article argues that most of the EC retail statistics presented by the research institutes or public organizations are likely to imply depreciation about the importance of EC.

From the consumer perspective and applying the broad definition of EC, there will be entirely different explanations. According to the Summer Retail Fluency Report issued by the CMO council (a California-based marketing trade group), for example, more than half of 322 shoppers queried as they left the consumer electronics stores said they had consulted the Internet before making their purchases there. Also among their findings, 21 percent of consumer electronics shoppers recognized the Internet as the most influential information source (TWICE, 2005-b). Obviously, this percentage of consumers (including buyers $\mathrm{A}, \mathrm{B}$, and $\mathrm{C}$ ) have spent their time and efforts to search information and to perform evaluation online, maybe with multiple visits to plenty of Web sites before their purchases. Their final decision should be significantly influenced by the online interactions no matter what kind of channel they choose to transact with at last. Compared to the online retail proportion of consumer electronics mentioned above (5 percent), the difference between these two proportions (accounts for 16 percent of total consumer electronics shoppers) could be referred to the paradox on definition of electronic commerce from consumers' perspective.

This gap can be explained by consumers who perform online interactions, but choose physical stores to purchase at last (as buyer C). From this argument, one shall be surprised at the fact that how big the gap is between academics' and practitioners' perceptions about EC and modern consumers.

Behavioral patterns under EC environment proposed in this paper earlier also could be applied to help marketers analyzing their targeted consumers in specific product category. For example, while trying to analyze the consumer electronics buyers' behavior, a binary type "product-price", or a triple application "product-price-convenience”, could be applied. While understanding the behavioral natures of targeted consumers' decision process, manufacturers can focus on providing detailed product information online to attract buyers' intention and to affect their product evaluation. Retailers, on the other hand, need to pay all their attentions to deliver packaged value under competitive price for a victory in consumers' channel evaluation. Researchers also can proceed with marketing studies to test the significance among variables regarding to the behavioral constructs and purchase 
decisions. A conceptual model with estimated relationships representing consumer electronics buyers' decision process is presented in Figure 2. Based on this model, some related hypotheses could be developed for further verifications.

In Figure 2, consumer electronics buyers' two-phased decision process is characterized by two critical activities: product evaluation and channel selection, as emphasis of manufacturers and retailers respectively. By estimation, product evaluation of consumer electronics buyers is affected by product, price, and convenience. In contrast, consumer's channel selection for buying consumer electronics is likely to be influenced by price and convenience. However, relationship between service and product evaluation seems to be not significant. Also, channel selection is not significantly influenced by product and service, for consumer electronics buyers. The empirical verification on this conceptual model is reserved for future studies. After checking the effect of each variable on consumer decision process for specific product category that marketers engaged in, a clearer look of consumer behavior will appear.

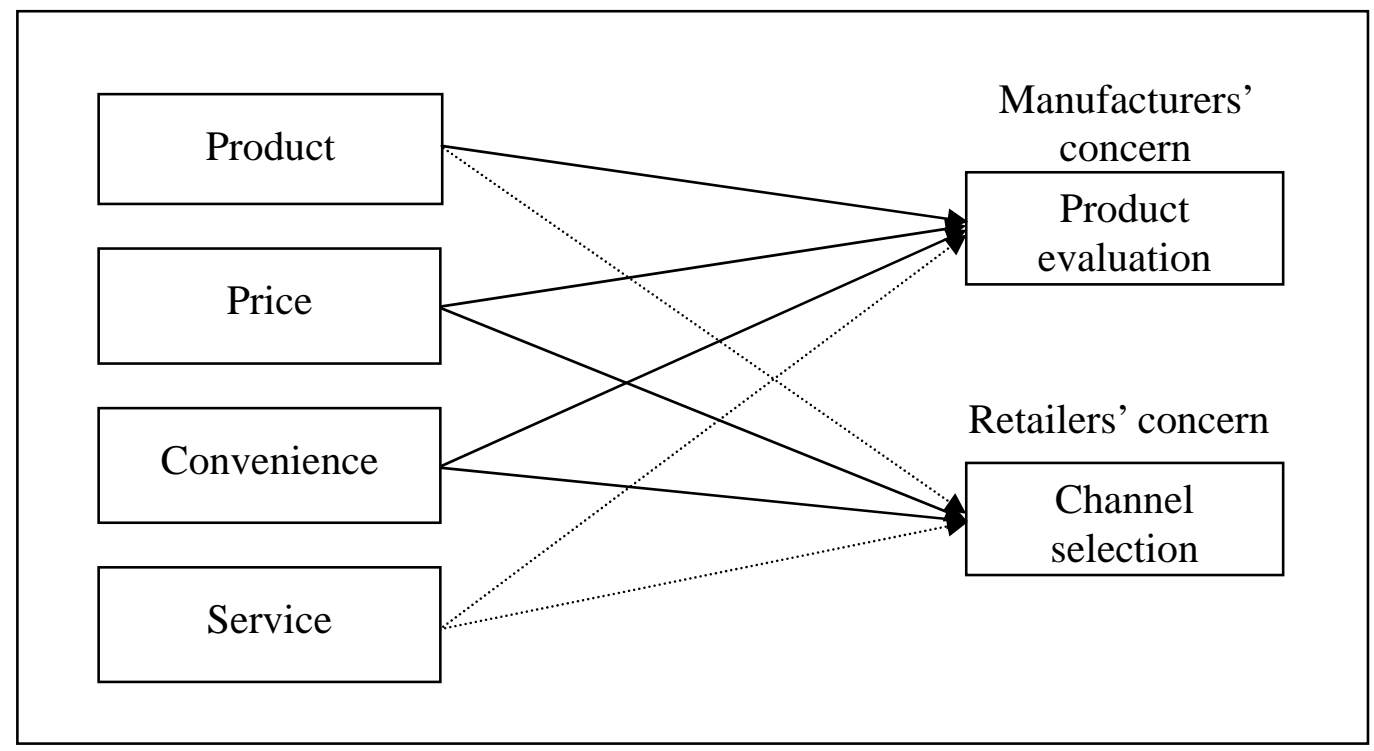

Figure 2 A conceptual model of consumer electronics buyer investigation

Anyway, managerial implication implied in this demonstration is worthy of special concerns from all the people involved. While trying to put marketing efforts on the modern compound marketplace, it is important to understand the impacts of EC and to clarify the consumers' behavioral characteristics within targeted segment before making any inference or decision. 


\section{CONCLUSION AND SUGGESTIONS}

Summarizing the discussions above, this article argues that there are at least two ways to define EC from the consumers' perspective:

1. A narrower definition of EC: Transactions conducted by buyers who perform online interactions with sellers and transact with electronic channels;

2. A broader definition of EC: Transactions conducted by buyers who performs online interactions with sellers and their final decisions are influenced accordingly, no matter which type of channel they choose to transact with at last.

People working in the related fields should be encouraged by this argument to grasp the key points about EC definitions based on their needs and problem settings. All the attempts to understand consumers could be achieved only if analyses are conducted from consumers' perspective.

This article brings up an interesting but momentous argument with EC definitions from the consumers' perspective. It provides insights for people who participate in related management fields of marketing and EC. Based on evidences from real world, this paper present a conceptual recognition about modern compound marketplace with four behavioral patterns of consumers existed in it. Furthermore, the opinion of this paper is demonstrated by an industrial case.

For the purpose to achieve further understanding about modern marketplace and to manage the transforming consumer behavior under the EC environment, the authors suggest that definition of EC should be clarified by marketing practitioners and researchers from the consumer perspective in order to prevent misleading descriptions and judgments. Consequently, consumer behavior should be reexamined according to the specific product categories for exploiting market opportunities. Based on this prerequisite, all the practical and academic efforts put on modern consumers and marketplaces might have chance to be actually valid and valuable.

\section{REFERENCES}

Chang, M.K., Cheung, W., \& Lai, V.S. (2005). Literature derived reference models for the adoption of online shopping. Information \& Management, 42(4), 543-559. Colecchia, A. (1999). Defining and measuring electronic commerce: Towards the development of an OECD methodology, Conference on the Measurement of Electronic Commerce, 6-8 December 1999, Singapore. 
Constantinides, E. (2004). Influencing the online consumer's behavior: the web experience. Internet Research, 14(2), 111-126.

Freitas, H., Oliveira, M., Jenkins, M. \& Popjoy, O. (1998). The focus group, a qualitative research method, ISRC Working Paper (Report No. 010298). Merrick School of Business, University of Baltimore.

Gupta, A., Su, B.C., \& Walter, Z. (2004). An empirical study of consumer switching from traditional to electronic channels: A purchase-decision process perspective. International Journal of Electronic Commerce, 8(3), 131-161.

Krueger, R. A., \& Casey, M. A. (2000). Focus groups: A practical guide for applied research (3rd ed.). Thousand Oaks, CA: Sage.

Lee, P.M. (2002). Behavioral model of online purchasers in e-commerce environment. Electronic Commerce Research, 2, 75-85.

McKay, J., \& Marshall, J. (2004). Strategic Management of E-Business. Milton, Old. Australia: John Wiley and Sons.

Schoenbachler, D. D., \& Gordon, G. L. (2002). Multi-channel shopping: understanding what drives channel choice. The Journal of Consumer Marketing, 19(1), 42-53.

Turban, E., King, D., Viehland, D., \& Lee, J. (2006). Electronic Commerce 2006: A Managerial Perspective. Upper Saddle River, NJ: Pearson Education Inc.

TWICE. (2005a). CE shopping continues shift to e-tail, 20(14). Retrieved Jul. 11, 2005, from http://www.twice.com/article/CA625217.html

TWICE. (2005b). Internet influences in-store sales, 20(23). Retrieved Nov. 7, 2005, from http://www.twice.com/article/CA6281840.html

U.S. Census Bureau. (2006). Quarterly Retail E-Commerce Sales: 4th Quarter 2005. Retrieved January 29, 2007 from http://www.census.gov/mrts/www/ data/html/05Q4.html 
